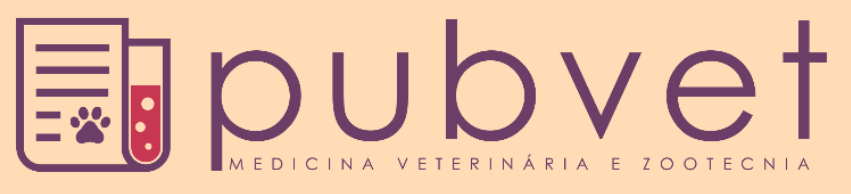

https://doi.org/10.31533/pubvet.v13n01a259.1-11

\title{
Emissão de metano na pecuária: relação causa-efeito e mecanismos modulatórios
}

\author{
Kelvin Gabriel Sant Anna de Paula ${ }^{1}$, Moisés Sena Pessoa ${ }^{2}$, Flávia, Oliveira Abrão ${ }^{3}$ \\ ${ }^{1}$ Instituto Federal Goiano, Campus Ceres/GO \\ ${ }^{2}$ Professor substituto (Zootecnia) no Instituto Federal Goiano - Campus Ceres/GO. \\ ${ }^{3}$ Professora efetiva do Instituto Federal Goiano (IF Goiano) \\ *Autor para correspondência, E-mail: flavia.abrao@ifgoiano.edu.br
}

RESUMO. A pecuária apresenta grande importância no cenário econômico brasileiro, desenvolvida em todos os estados e ecossistemas do País, sendo que o setor de corte brasileiro apresenta uma ampla gama de sistemas de produção. A produção de carne bovina brasileira é principalmente de sistemas de produção em pastagem, sendo que o Brasil possui uma área de 180 milhões de hectares de pasto, onde mais da metade deste total apresentam algum grau de degradação do solo e da pastagem, principalmente em estágios avançados. A emissão de metano pelos ruminantes é responsável por $22 \%$ deste gás na atmosfera, constituindo a terceira maior fonte em escala global. $\mathrm{O}$ gás metano $\left(\mathrm{CH}_{4}\right)$ possui uma participação significativa de $15 \%$ no aquecimento global, contudo o Brasil apresenta grande potencial de redução da emissão do gás metano, através da melhoria dos índices produtivos de sua pecuária. Melhorias na alimentação e na genética dos animais resultam numa menor emissão de $\mathrm{CH}_{4}$ durante o ciclo de vida do animal. Além disso, essas melhorias resultam numa maior produção de carne resultando em um duplo benefício: o ambiental e o econômico. $\mathrm{O} \mathrm{CH}_{4}$ é considerado o segundo maior contribuinte para o aquecimento da terra, através da absorção de radiação infravermelha em atmosfera ficando atrás somente do dióxido de carbono $\left(\mathrm{CO}_{2}\right)$. O aumento de sua concentração na atmosfera está intimamente ligado com a expansão mundial da população humana, visto que as principais fontes emissoras, além da fermentação entérica são os aterros sanitários, uso de combustíveis fósseis e práticas agrícolas. Dessa forma, objetivou-se com a presente revisão levantar os apontamentos da literatura científica acerca da produção de metano vinculados aos ruminantes e, traçar mecanismos modulatórios que permitam a produção desses animais com altos níveis produtivos e baixa emissão desse gás.

Palavras-chave: aquecimento, atmosfera, alimentação animal, gás

\section{Emission of methane in livestock: cause-effect relationship and modulatory mechanisms}

Abstract. Livestock farming has great importance in the Brazilian economic scenario, developed in all states and ecosystems of the country, and the Brazilian sector presents a wide range of production systems. Brazilian beef production is mainly from pasture production systems, with Brazil having an area of 180 million hectares of pasture, where more than half of this total presents some degree of soil degradation and pasture, mainly in stages advanced. The emission of methane by ruminants accounts for $22 \%$ of this gas in the atmosphere, making it the third largest source on a global scale. Methane gas $\left(\mathrm{CH}_{4}\right)$ has a significant participation of $15 \%$ in global warming, but Brazil has a great potential to reduce the emission of methane gas by improving the productivity indexes of its livestock. Improvements in animal feeding and genetics result in less $\mathrm{CH}_{4}$ emission during the 
animal's life cycle. In addition, these improvements result in increased meat production resulting in a double benefit: the environmental and the economic. $\mathrm{CH}_{4}$ is considered to be the second largest contributor to the earth's heating by absorbing infrared radiation into atmosphere behind only carbon dioxide $\left(\mathrm{CO}_{2}\right)$. The increase in its concentration in the atmosphere is closely linked to the worldwide expansion of the human population, since the main sources of emissions, besides enteric fermentation are landfills, fossil fuel use and agricultural practices. Thus, the objective of this review was to present the scientific literature about the production of methane bound to ruminants and to design modulatory mechanisms that allow the production of these animals with high production levels and low emission of this gas.

keywords: heating, atmosphere, animal feed, gas

\section{Emisión de metano en la ganadería: relación causa-efecto y mecanismos moduladores}

Resumen. La ganadería presenta gran importancia en el escenario económico brasileño, desarrollada en todos los estados y ecosistemas del país, siendo que el sector de carne brasileño presenta una amplia gama de sistemas de producción. La producción de carne bovina brasileña es principalmente de sistemas de producción en pastoreo, siendo que Brasil posee un área de 180 millones de hectáreas de pasto, donde más de la mitad de este total presentan algún grado de degradación del suelo y de pastos, principalmente en etapas avanzada. La emisión de metano por los rumiantes es responsable del $22 \%$ de este gas en la atmósfera, constituyendo la tercera mayor fuente a escala global. El gas metano $\left(\mathrm{CH}_{4}\right)$ posee una participación significativa del $15 \%$ en el calentamiento global, sin embargo, Brasil presenta un gran potencial de reducción de la emisión del gas metano, a través de la mejora de los índices productivos de su ganadería. Las mejoras en la alimentación y la genética de los animales resultan en una menor emisión de $\mathrm{CH}_{4}$ durante el ciclo de vida del animal. Además, estas mejoras resultan en una mayor producción de carne resultando en un doble beneficio: el ambiental y el económico. $\mathrm{El} \mathrm{CH}_{4}$ es considerado el segundo mayor contribuyente para el calentamiento de la tierra, a través de la absorción de radiación infrarroja en atmósfera quedando atrás solamente del dióxido de carbono $\left(\mathrm{CO}_{2}\right)$. El aumento de su concentración en la atmósfera está íntimamente ligado con la expansión mundial de la población humana, ya que las principales fuentes emisoras, además de la fermentación entérica, son los rellenos sanitarios, el uso de combustibles fósiles y las prácticas agrícolas. De esta forma, se objetivó con la presente revisión levantar los apuntes de la literatura científica acerca de la producción de metano vinculados a los rumiantes y, trazar mecanismos moduladores que permitan la producción de esos animales con altos niveles productivos y baja emisión de ese gas.

Palabras clave: calentamiento, atmósfera, alimentación animal, gas

\section{Introdução}

A pecuária apresenta grande importância no cenário econômico brasileiro, desenvolvida em todos os estados e ecossistemas do país. A pecuária de corte brasileira apresenta uma ampla gama de sistemas de produção (Ferraz \& Felício, 2010). Estes variam desde uma pecuária extensiva, suportada por pastagens nativas e cultivadas de baixa produtividade e pouco uso de insumos, até uma pecuária dita intensiva, com pastagens de alta produtividade, suplementação alimentar em pasto e confinamento (ANUALPEC, 2017).

No cenário mundial o Brasil ocupa a segunda posição no ranking mundial na criação de bovinos (ANUALPEC, 2017; FAPRI, 2017). o rebanho brasileiro é estimado em aproximadamente 218 milhões de cabeças suplantado apenas pela Índia. Dessa forma, é considerado o maior rebanho comercial do mundo. A agropecuária desde o começo do processo de colonização do território brasileiro desempenhou função importante na estrutura produtiva. Primeiramente foi primordial no abastecimento dos núcleos urbanos e, em seguida, expandiu-se em direção ao sertão nordestino, onde o gado passou a 
ser criado solto em pastagens naturais (Pinedo et al., 2009). A bovinocultura brasileira é principalmente composta pelos sistemas de produção em pastagem, esta ocupa uma área de 180 milhões de hectares de pasto, onde mais da metade deste total apresentam algum grau de degradação do solo e da pastagem, principalmente em estágios avançados (Ferraz \& Felício, 2010).

Os sistemas de produção animal cada vez mais têm recebido atenção, pois contribuem com a elevação das concentrações dos Gases de Efeito Estufa (GEE) na atmosfera: metano $\left(\mathrm{CH}_{4}\right)$, dióxido de carbono $\left(\mathrm{CO}_{2}\right)$ e óxido nitroso $\left(\mathrm{NO}_{2}\right)$. As emissões são provenientes tanto pela fermentação entérica quanto da deposição de excreta em pastagens ou da utilização do esterco como fertilizante (armazenamento e utilização) (Monteiro et al., 2018; Pinedo et al., 2009). Segundo a Monteiro et al. (2018) a emissão de metano pelos ruminantes é responsável por $22 \%$ deste gás na atmosfera, constituindo a terceira maior fonte em escala global. Berchielli et al. (2012) afirmaram que o metano e responsável por $15 \%$ do aquecimento global. Monteiro et al. (2018) constataram que as emissões totais por categoria dos animais refletem o desempenho zootécnico do rebanho, uma vez que o metano tem relação direta com a eficiência da fermentação ruminal em virtude da perda de carbono e, consequentemente, perda de energia, determinando menor desempenho animal.

O Brasil apresenta grande potencial de redução da emissão do gás metano, pela melhoria dos índices produtivos de sua pecuária. Melhorias na alimentação e na genética dos animais resultam em uma menor emissão de $\mathrm{CH}_{4}$ durante o ciclo de vida do animal. Além disso, essas melhorias direcionam a uma maior produção de carne resultando em um duplo benefício: o ambiental e o econômico (Cohn et al., 2011).

Objetivou-se por meio desta revisão verificar e contrastar resultados da literatura científica que avaliam a emissão de metano nos diferentes sistemas de produção e alimentação animal.

\section{Produção de metano}

$\mathrm{O}$ efeito estufa é um mecanismo natural que ajuda mantém a temperatura do planeta entre 14 a $16^{\circ} \mathrm{C}$ (Ramírez-Restrepo et al., 2016). No entanto, a preocupação global não está voltada para o aquecimento causado por fontes naturais de GEE, sem o qual o planeta apresentaria temperaturas muito baixas para suportar, mas sim no aumento das concentrações de GEE na atmosfera por ação do homem, que causam o aquecimento global adicional e, consequentemente, as mudanças climáticas (Johnson \& Johnson, 1995; Massé et al., 2008).

O metano está em segundo lugar como gás que mais contribui para o aquecimento do planeta terra, através da absorção de radiação na atmosfera perdendo somente para o dióxido de carbono $\left(\mathrm{CO}_{2}\right)$. $\mathrm{O}$ aumento de sua concentração na atmosfera está fortemente ligado com a expansão da população humana, visto que as principais emissoras deste gás, além da fermentação entérica são os aterros sanitários, uso de combustíveis fósseis e práticas agrícolas (Zotti \& Paulino, 2009). O metano é produzido por arqueobactérias, estas bactérias as Archaeas, também conhecidas como metanogênicas, pertencem ao sub-reino Archaea (Huws et al., 2018). Essas fazem parte de um grupo distinto de microrganismos, possuindo cofatores (coenzimas M, F420, F430) e lipídeos (éteres de isopranil glicerol) únicos, e possuem uma parede celular composta por pseudomureína, proteína, glicoproteína ou heteropolissacarídeos e sequência de nucleotídeos que indica uma evolução inicial distinta das bactérias (Ishino et al., 1998). O metano é produzido no rúmen como produto de fermentação normal de alimentos para animais. Apesar de que a produção de metano também possa ocorrer além do rúmen no trato gastrointestinal inferior, como em não ruminantes, $89 \%$ do metano emitido pelos ruminantes é produzido no rúmen e exalado pela boca e nariz (Benchaar et al., 1998; Ellis et al., 2007). O ruminante sofre uma perda de energia derivada da alimentação ingerida de aproximadamente $2-12 \%$, a perda de metano para a atmosfera varia de acordo com a dieta e as espécies de ruminantes (Hook et al., 2010).

Entre as espécies metanogênicas isoladas em diversos habitats anaeróbios, somente duas, Methanobrevibacter ruminantium e Methanosarcina sp. foram encontradas em grande número no rúmen, apresentando grande importância no metabolismo do metano no processo digestivo dos ruminantes (McAllister et al., 1996). As Archaeas são encontradas associadas a protozoários ciliados e com bactérias. Espécies metanogênicas apresentam boa capacidade de sintetizar $\mathrm{CH}_{4}$ a partir de $\mathrm{H}_{2} \mathrm{e}$ $\mathrm{CO}_{2}$ para atender suas necessidades energéticas e o seu desenvolvimento (Miller, 1995) (Figura 1). Estas 
também têm a capacidade de sintetizar $\mathrm{CH}_{4}$ a partir do formato e, em menor grau, a partir do metanol, mono-, di- e tri-metilamina e acetato, mas é a redução do $\mathrm{CO}_{2}$ a via preferencial.

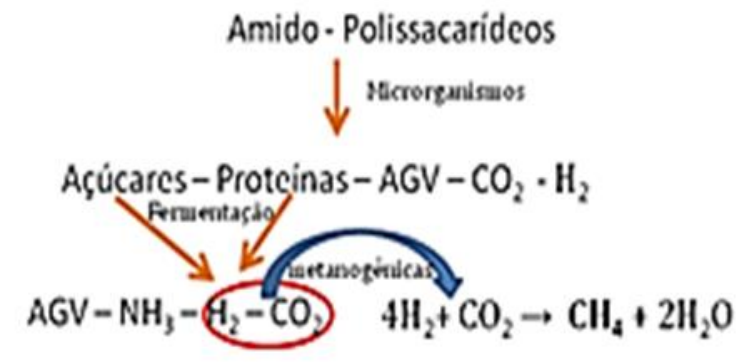

Figura 1. Via metabólica de produção de metano ruminal. Fonte: Miller (1995).

A produção de $\mathrm{CH}_{4}$ a partir da matéria orgânica no rúmen ocorre em anaerobiose e envolve um consórcio de microrganismos ruminais, com a etapa final realizada pelas metanogênicas (McAllister et al., 1996). Em ruminantes, a fermentação de alimentos ingeridos produz ácidos graxos voláteis (AGVs), amônia, gases (dióxido de carbono e metano) e células microbianas. Para o ruminante, os AGVs constituem a maior fonte de energia ( 65 a $75 \%$ da energia metabolizável ingerida). Entretanto, a produção de dióxido de carbono e metano, representa grande perda de energia ingerida no alimento (Berchielli et al., 2011). As bactérias metanogênicas então removem $\mathrm{H}_{2}$ e reduzem $\mathrm{CO}_{2}$ para formar $\mathrm{CH}_{4}$. O metano é um subproduto da fermentação ruminal e trabalha como um aceptor de elétrons (Kozloski, 2011). Este mantém a concentração baixa de hidrogênio no rúmen, o que permite às bactérias metanogênicas promover o crescimento de outras espécies bacterianas e prover uma fermentação mais eficiente.

Quando a emissão de $\mathrm{CH}_{4}$ por unidade de alimento ingerido (MJ de metano/100MJ de energia bruta ingerida) é contrastada com o consumo de MS, encontra-se uma moderada correlação negativa ( $\mathrm{r}=$ 0.597), indicando que com o aumento percentual do consumo a energia perdida $\mathrm{como} \mathrm{CH}_{4}$ diminui. Isso sugere que para uma eficiente produção animal e redução das emissões de $\mathrm{CH}_{4}$ serem vantajosas, a alimentação dos animais deve ser acima da ingestão de manutenção (Zotti \& Paulino, 2009). Além disso, sabe-se que do metano produzido pela fermentação entérica no rúmen, $95 \%$ é liberado para o ambiente por eructação e apenas 5\% pelo ânus (Johnson \& Johnson, 1995; Pinares-Patiño et al., 2007). As estimativas de emissão de metano para o gado de corte e leite oscilam em torno de $57 \mathrm{~kg}$ por animal, para os ovinos e caprinos $5 \mathrm{~kg}$ e os suínos em torno de $1 \mathrm{~kg}$ por animal, sendo que a fermentação entérica é responsável por $22 \%$ das emissões de metano, $3,3 \%$ do total de gases de efeito estufa (Zotti \& Paulino, 2009).

No relatório da Organização para Agricultura e Alimentação (FAO, Food and Agricultural Organization) das Nações Unidas, intitulado Livestock's long shadow editado por Steinfeld et al. (2006) relata-se que a produção pecuária mundial produz mais $\mathrm{CO}_{2}$ (ou equivalente) do que todo o sistema de transporte no mundo, quando se considera o desmatamento e a queimada de florestas, a produção de metano pela fermentação ruminal e a produção de metano pela fermentação de dejetos (Monteiro et al., 2018). Contudo, deve-se ter cuidado ao realizar tais afirmativas, uma vez que é na produção animal, quando em sistemas extensivos que se tem mitigação de gases pela incorporação e estoque de carbono no solo em pastagens bem manejadas, a eficiência de raças precoces, que reduzem a permanência do gado no pasto. Ou seja, pastagens quando bem manejadas podem minimizar a emissão de metano além de sequestrar carbono.

\section{Estratégias de redução de emissão de metano por ruminantes}

Reduzir a emissão de metano é extremamente necessário para diminuir os efeitos da agropecuária brasileira na produção de gases de efeito estufa. No Brasil, o metano de origem entérica equivale $63 \%$ da emissão de metano de todo o país. O metano è o gás responsável por mais de $50 \%$ das emissões do setor agropecuário de acordo com a Segunda Comunicação Nacional sobre GEE do Ministério da Ciência, Tecnologia e Inovação. 
As principais táticas para reduzir a emissão de GEE incluem: melhoria dos índices produtivos e reprodutivos (diminuição da idade do abate, ao primeiro parto e do intervalo entre partos); reduzir o número de animais de reposição; aumento da longevidade das matrizes; aumento da qualidade genética dos animais e das forrageiras; seleção de ruminantes com melhor CAR (consumo alimentar residual), otimização da formulação de dietas; uso de aditivos e suplementos alimentares; melhoria da eficiência de conversão alimentar; oferta de água com mais qualidade; melhoria do manejo zootécnico; aprimoramento da sanidade animal (controle de parasitas, doenças e vacinas); além da busca pelo bem estar animal (Beauchemin et al., 2008; Berndt \& Tomkins, 2013; Boadi et al., 2004; Hegarty \& Gerdes, 1999; Smith et al., 2007). Segundo Hook et al. (2010) a mitigação se dá de forma efetiva por duas vias: uma direta, pelo efeito sobre os microrganismos metanogênicos, ou uma indireta, causado pelo impacto da estratégia sobre a disponibilidade de substrato para a metanogênese, geralmente através de um efeito sobre outras populações microbianas do rúmen. Zotti \& Paulino (2009) respaldaram que a qualidade nutricional dos alimentos tem-se tornado um dos principais recursos para mitigação da emissão de $\mathrm{CH}_{4}$, sendo gerados por muitas pesquisas resultados que indicam o uso de concentrados como componente mais efetivo nesta redução.

\section{Volumoso $\mathrm{x}$ concentrado}

A substituição de carboidratos estruturais (celulose e hemicelulose) por carboidratos não fibrosos (amidos e açúcares) faz com que ocorram mudanças físico-químicas no rúmen e em sua população microbiana, fazendo com que ocorra um maior crescimento de bactérias amilolíticas e o na produção de propionato e redução do acetato (Berchielli et al., 2011). Assim quando o animal recebe dietas com maior concentração de amido, ocorre queda do $\mathrm{pH}$, tornando um ambiente mais hostil para a sobrevivência de metanogênicas, devido à baixa produção de $\mathrm{H}_{2}$ resultante dessa fermentação. Então, menos $\mathrm{CH}_{4}$ é produzido por unidade de amido do que por unidade de carboidrato estrutural (Zotti \& Paulino, 2009).

O manejo de forrageiras também interfere nos níveis de emissão de metano. Pastagens degradadas gera ineficiência ao processo produtivo, ocasionando maiores emissões de metano por unidade de produto de origem animal produzido, enquanto que pastagens produtivas e manejadas adequadamente, além de propiciarem condições favoráveis para aumentos significativos no desempenho animal e índices zootécnicos, também podem absorver grande parte do carbono emitido pela atividade pecuária, tornando-se componente importante no balanço de GEE (Monteiro et al., 2018).

O IPCC (2006) utiliza para a América Latina uma estimação padrão (default) de liberação de $56 \mathrm{~kg}$ de metano por animal por ano para o gado de corte com $430 \mathrm{~kg}$ de peso vivo. Na revisão de literatura realizada por Monteiro et al. (2018) estima-se uma produção de $46,1 \mathrm{~kg} \mathrm{CH}_{4}$.ano ${ }^{-1}$ para vacas de corte com média de peso de 400 a $430 \mathrm{~kg}$ e de $66,8 \mathrm{~kg} \mathrm{CH}_{4} \cdot \mathrm{ano}^{-1}$, para touro com média de peso de $700 \mathrm{~kg}$. DeRamus et al. (2003) avaliaram emissão de metano de bovino, em confinamento, com dieta de Brachiaria brizantha, machos e encontraram valores médios de $50 \mathrm{~kg} \mathrm{CH}_{4} \cdot \mathrm{ano}^{-1}$ para animais com 400 $\mathrm{kg}$. Berchielli et al. (2003) avaliaram a adição de concentrado na dieta de bovinos, encontrando aumento na produção de metano com a adição de até $30 \%$ de concentrado na dieta, e redução com $60 \%$ de adição, como pode ser observado na tabela 1. O trabalho de Berchielli et al. (2003) demostrou que a diminuição na produção de metano produzido devido à adição de concentrado ocorre, porém, dependendo da proporção de volumoso:concentrado. O que contrasta com os outros autores citados. Isso quando se leva em consideração apenas a produção de metano em determinado período, pois se for considerar o ganho na produção animal devido a suplementação e a diminuição no tempo de vida do animal a produção de metano é ainda menor.

Tabela 1. Efeito da relação volumoso:concentrado sobre o consumo de matéria seca, pH ruminal e produção de metano

\begin{tabular}{lcccc}
\hline \multirow{2}{*}{ Parâmetro } & \multicolumn{3}{c}{ Tratamentos } & \multirow{2}{*}{ CV, \% } \\
\cline { 2 - 4 } & $100: 0$ & $70: 30$ & $40: 60$ & 6,75 \\
CMS (Kg/d) & 5,55 & 7,98 & 8,75 & 1,48 \\
$\mathrm{pH}^{1}$ & 6,96 & 6,67 & 6,44 & 9,25 \\
${\text { Metano }(\mathrm{g} / \mathrm{h})^{2}}^{2}$ & 5,22 & 6,25 & 5,85 & \\
\hline
\end{tabular}

${ }^{1}$ Efeito linear $(\mathrm{P}<0,01) .{ }^{2}$ Efeito quadrático $(\mathrm{P}<0,01)$. 


\section{Aditivos moduladores do metabolismo ruminal sobre a produção de metano}

Melhorias na dieta com o uso de aditivos como probióticos, ionóforos, leveduras, óleos essenciais, taninos, anticorpos policlonais, e/ou suplementação com gorduras, principalmente as insaturadas vêm sendo empregados como alternativas para redução da produção de metano, sendo estes os principais métodos diretos para diminuição da metanogênese (Gattass et al., 2008; Lascano \& Cárdenas, 2010; Steinfeld et al., 2006; Zinn, 1987). Os principais aditivos relatados e comprovados cientificamente que interferem na fermentação ruminal e consequentemente reduzem a perda de energia nos sistemas de produção, são: ionóforos (Bergen \& Bates, 1984; Callaway et al., 2003), ácidos orgânicos (Askar et al., 2011), extratos de plantas (Geraci et al., 2012; Hart et al., 2008) e óleos essenciais (Benchaar et al., 2008a; Benchaar et al., 2008b; Ornaghi et al., 2017).

Aditivos são definidos pelo Ministério da Agricultura, Pecuária e Abastecimento como substâncias, microrganismos ou produtos formulados intencionalmente adicionados ao alimento, com a finalidade de melhorar as suas características, intensificar o desempenho dos animais, atender as necessidades nutricionais ou que tenha efeito anticoccidiano.

\section{Lipídeos insaturados}

Os ácidos graxos insaturados possuem uma ou mais duplas ligações, apresentam-se geralmente líquidos à temperatura ambiente e estão presentes em alta concentração em óleos de origem vegetal. $\mathrm{O}$ fornecimento de lipídeos insaturados está associado à redução na produção de $\mathrm{CH}_{4}$ no rúmen por exercer ação deletéria sobre as metanogênicas e protozoários ruminais e, consumir $\mathrm{H}_{2}$ pelo processo de biohidrogenação (Zotti \& Paulino, 2009). Lipídeos insaturados atuam exercendo ação deletéria sobre as Archaeas, sendo que a intensidade com que ocorre a inibição da produção de $\mathrm{CH}_{4}$ é determinada pelo grau de saturação da gordura utilizada e a quantidade suplementada (Palmquist, 1989; Palmquist \& Jenkins, 1980; Palmquist \& Mattos, 2011). Como fonte de ácidos graxos insaturados tem-se explorado a utilização da canola (Albuquerque et al., 2009) com 60\% de ácido oleico (C18:1), da soja (Ito et al., 2010) com 50\% de linoleico (C18:2) e da linhaça (Jiménez-Colmenero, 2007) com 47\% de linolênico (C18:3). Adicionalmente, o óleo de coco e o óleo de palma, apesar de serem fontes de origem vegetal, possuem ácidos graxos saturados com 45\% de ácido láurico (C12:0) e 40\% de palmítico (C16:0), respectivamente, podendo também serem usados para manipular a fermentação ruminal (Hristov et al., 2000).

\section{Ionóforos}

Os ionóforos foram inicialmente, e ainda são utilizados como coccidiostáticos na avicultura, mas descobriu-se que a suplementação oral melhorava o desempenho de ruminantes (Zotti \& Paulino, 2009). Tornando-se aditivos empregados na alimentação de ruminantes que podem reduzir a produção de $\mathrm{CH}_{4}$ em até $25 \%$ e a ingestão de alimentos, em $4 \%$, sem afetar o desempenho animal, principalmente a monensina utilizada na suplementação de ruminantes (Tedeschi et al., 2003).

O efeito dos ionóforos deve-se à alteração na fermentação ruminal, com alterações na proporção de AGV produzidos e na concentração de amônia, processos chaves que afetam diretamente o metabolismo de energia e proteína animal. Além disso, esses aditivos aumentam a retenção de energia fermentada no rúmen devido uma alteração no padrão de fermentação, e decorrente diminuição das perdas pelo $\mathrm{CH}_{4}$ (Bergen \& Bates, 1984; Callaway et al., 2003; Zotti \& Paulino, 2009).

\section{Óleos essenciais de plantas:}

Óleos essenciais são metabólitos secundários responsáveis pelo odor e cor de algumas plantas. As pesquisas conduzidas até o momento indicam a possibilidade da utilização de óleos essenciais para manipulação da fermentação ruminal (Pereira, 2013).

Os óleos essenciais (terpenóides e fenilpropanóides) apresentam a capacidade de interação com os lipídios da membrana celular e das mitocôndrias das bactérias, devido a sua natureza hidrofóbicas, o que por sua vez tem a capacidade de altera a estrutura das membranas, tornando-as mais fluidas, permeáveis e permitindo o extravasamento de íons e outros conteúdos citoplasmáticos. Em muitos casos as bactérias conseguem sobreviver usando o mecanismo de bomba iônica e a morte celular não ocorre, 
mas grande quantidade de energia é desviada para essa função e o crescimento bacteriano é reduzido (Calsamiglia et al., 2007).

\section{Saponinas}

Vários produtos naturais têm sido empregados como aditivos alimentares com potencial de mitigação de metano entérico em ruminantes, dentre estes compostos, destacam-se as saponinas (Goel \& Makkar, 2012; Hess et al., 2003). As saponinas diminuem a degradação de proteínas e favorece a síntese de proteína e biomassa microbiana, esses dois processos produzem uma quantidade menor de $\mathrm{H}_{2}$ para a metanogênese (Martin et al., 2010). Mas o principal mecanismo que diminui a produção de metano das saponinas e o efeito tóxico sobre protozoários ciliados. As saponinas emulsificam os lipídeos da membrana dos protozoários, mudando a permeabilidade, e causando apoptose (Wallace et al., 2002).

\section{Probióticos}

O MAPA, pela instrução normativa $\mathrm{n}^{\circ} 13$, define os probióticos como sendo cepas de microrganismos vivos (viáveis), que agem como auxiliares na recomposição da microbiota do trato digestivo dos animais, contribuindo para o seu equilíbrio. Os probióticos podem ser uma espécie de suplementação alimentar constituídos de culturas puras ou compostas de microrganismos vivos com a capacidade de se desenvolver no trato intestinal como promotor de crescimento devido ao estimulo a microbiota natural do hospedeiro. Seus mecanismos de ação não são totalmente conhecidos, os principais são: competição por sitio de ligação, produção de substancias antibacteriana, competição por nutriente e estimulo do sistema imunológico (Boadi et al., 2004; Chiquette \& Benchaar, 1998). As leveduras utilizam os metabolitos nitrogenados e com isso aumenta as concentrações de propionato reduzindo a produção de metano (Chaucheyras-Durand et al., 2008; Issakowicz et al., 2013; Zeoula et al., 2011).

\section{Prebióticos}

De acordo com MAPA, os prebióticos, são ingredientes que não são digeridos pelas enzimas digestivas do hospedeiro, mas que são fermentados pela microbiota do trato digestório dos animais, contribuindo para o seu equilíbrio. Os prebióticos agem ativando e ou estimulando o desenvolvimento de algum grupo de bactérias benéficas do trato intestinal (Kesarcodi-Watson et al., 2008), assim agindo junto aos probióticos produzem o alimento das bactérias probióticas. Por sua vez os prebióticos não devem ser metabolizados e/ou absorvidos no trato gástrico superior, devem servir de substrato para as bactérias benéficas do intestino, serem capazes de modificar a microbiota de maneira favorável a saúde do hospedeiro induzindo efeitos benéficos e sistêmicos e/ou no lúmen intestinal do hospedeiro, assim estimulando o crescimento de bactérias intestinais benéficas. Também reduzem o $\mathrm{pH}$ pelo aumento de ácidos orgânicos presentes nos cecos (Albino et al., 2006; Flemming \& Freitas, 2005).

\section{Outros fatores de interferência sobre a produção de metano}

Segundo Monteiro et al. (2018) uma maior taxa de lotação, melhoria na qualidade do alimento oferecido e a redução na idade de abate resultaram numa redução na emissão de metano de $2,75 \mathrm{~kg} / \mathrm{kg}$ de carcaça para $1,76 \mathrm{~kg} / \mathrm{kg}$ de carcaça. Assim devido as melhorias na dieta e tempo de terminação (engorda) implicaram em menor emissão de $\mathrm{N}_{2} \mathrm{O}$ por indivíduo e por carcaça produzida. Essa redução é fruto do menor período de engorda, o que resulta numa menor idade ao abate.

Nos trabalhos publicados por Zhai et al. (2015) e Monteiro et al. (2018) foi constatado que ao manejar a pastagem e aumentar a produção de carne por hectare à emissão do gás metano reduziu de $1,75 \mathrm{~kg} / \mathrm{kg}$ de carcaça para $1,29 \mathrm{~kg} / \mathrm{kg}$ de carcaça, resultando na redução de $26,39 \%$ em relação ${ }^{\mathrm{a}}$ um sistema menos produtivo, e ao introduzir o confinamento as emissões reduziram de $1,29 \mathrm{~kg} / \mathrm{kg}$ de carcaça para $1,01 \mathrm{~kg}$ carcaça, ou uma redução de 20,28 \%. Ocorrendo então uma redução de 60,37\% entre o sistema menos intensivo e o cenário mais intensivo. De acordo com esses mesmos autores, a queda nas emissões totais dos diferentes rebanhos reflete a melhoria na alimentação dos animais (alimentos com melhor digestibilidade), de forma que se comparando as emissões dos diferentes sistemas, observa-se que a produção de $\mathrm{CH}_{4}$ no cenário menos intensivo, para todos os animais, pode ser de $25 \mathrm{~kg}, 50 \%$ superior 
a do cenário do confinamento, que emitiu $17 \mathrm{~kg}$ de $\mathrm{CH}_{4}$ (Monteiro et al., 2018; Muetzel \& Clark, 2015; Zhai et al., 2015).

\section{Considerações finais}

Os ruminantes, devido seu sistema fisiológico digestivo, estão entre os emissores de metano, contribuindo para o aquecimento global e prejudicando o equilíbrio do meio ambiente; porém é notório que este metano exerce papel fundamental pra o bom funcionamento do rúmen. Devido a isto os pecuaristas devem optar por formas estratégicas de controle desta emissão, sem comprometimento dos índices produtivos. Dentre as principais estratégias destacam-se: melhorar o valor nutritivo da alimentação dada aos animais em pastejo, equilibrar a dieta com concentrados, ou fornecer pastagens de melhor qualidade (melhor digestibilidade). Com isto, consequentemente haverá uma melhora sobre a microbiota ruminal, aumentando a eficiência do processo fermentativo no rúmen, com decréscimo na metanogênese por unidade de carboidrato degradado.

\section{Referências bibliográficas}

Albino, L. F. T., Feres, F. A., Dionizio, M. A., Rostagno, H. S., Vargas Júnior, J., G,, Carvalho, D., C,O, Costa, C. H. (2006). Uso de prebióticos à base de mananoligossacarídeo em rações para frangos de corte. Revista Brasileira de Zootecnia, 35(3), 742-749.

Albuquerque, K. P., Prado, I. N., Cavalieri, F. L. B., Rigolon, L. P., Prado, R. M. \& Rotta, P. P. (2009). Fatty acid composition in blood plasma and follicular liquid in cows supplemented with linseed or canola grains. Asian-Australasian Journal of Animal Sciences, 22(9), 1248-1255.

ANUALPEC. (2017). Anuário da Pecuária Brasileira (20th ed. Vol. 1). São Paulo, SP, Brasil: Instituto FNP.

Askar, A. R., Guada, J. A., González, J. M., de Vega, A. \& Castrillo, C. (2011). Effects of sodium bicarbonate on diet selection and rumen digestion by growing lambs individually fed whole barley grain and a protein supplement at their choice. Animal Feed Science and Technology, 164(1-2), 4552.

Beauchemin, K. A., Kreuzer, M., O'Mara, F. \& McAllister, T. A. (2008). Nutritional management for enteric methane abatement: a review. Animal Production Science, 48(2), 21-27.

Benchaar, C., Calsamiglia, S., Chaves, A. V., Fraser, G. R., Colombatto, D., McAllister, T. A. \& Beauchemin, K. A. (2008a). A review of plant-derived essential oils in ruminant nutrition and production. Animal Feed Science and Technology, 145(1-4), 209-228.

Benchaar, C., McAllister, T. A. \& Chouinard, P. Y. (2008b). Digestion, ruminal fermentation, ciliate protozoal populations, and milk production from dairy cows fed cinnamaldehyde, quebracho condensed tannin, or yucca schidigera saponin extracts. Journal of Dairy Science, 91(12), 47654777. doi: 10.3168/jds.2008-1338

Benchaar, C., Rivest, J., Pomar, C. \& Chiquette, J. (1998). Prediction of methane production from dairy cows using existing mechanistic models and regression equations. Journal of Animal Science, 76(2), 617-627.

Berchielli, T. T., Messana, J. D. \& Canesin, R. C. (2012). Produção de metano entérico em pastagens tropicais. Revista Brasileira de Saúde e Produção Animal, 13(4), 954-968.

Berchielli, T. T., Pedreira, M. D. S., Oliveira, S. D. O., Primavesi, O., Limas, M. \& Frigueto, R. (2003). Determinação da produção de metano e PH ruminal em bovinos de corte alimentados com diferentes relações volumoso: concentrado. Paper presented at the Embrapa Pecuária Sudeste-Artigo em anais de congresso, Santa Maria, Rio Grande do Sul.

Berchielli, T. T., Pires, A. V. \& Oliveira, S. G. (2011). Nutrição de Ruminantes. Jaboticabal, Brazil: FUNEP.

Bergen, W. G. \& Bates, D. B. (1984). Ionophores: their effect on production efficiency and mode of action. Journal of Animal Science, 58(6), 1465-1483.

Berndt, A. \& Tomkins, N. W. (2013). Measurement and mitigation of methane emissions from beef cattle in tropical grazing systems: a perspective from Australia and Brazil. Animal, 7(2), 363-372. 
Boadi, D., Benchaar, C., Chiquette, J. \& Massé, D. (2004). Mitigation strategies to reduce enteric methane emissions from dairy cows: Update review. Canadian Journal of Animal Science, 84(3), 319-335.

Callaway, T. R., Edrington, T. S., Rychlik, J. L., Genovese, K. J., Poole, T. L., Jung, Y. S., Nisbet, D. J. (2003). Ionophores: their use as ruminant growth promotants and impact on food safety. Current issues in intestinal microbiology, 4(2), 43-51.

Calsamiglia, S., Busquet, M., Cardozo, P. W., Castillejos, L. \& Ferret, A. (2007). Invited review: essential oils as modifiers of rumen microbial fermentation. Journal of Dairy Science, 90(6), 25802595.

Chaucheyras-Durand, F., Walker, N. D. \& Bach, A. (2008). Effects of active dry yeasts on the rumen microbial ecosystem: Past, present and future. Animal Feed Science and Technology, 145(1-4), 526.

Chiquette, J. \& Benchaar, C. (1998). Effect of diet and probiotic addition on chemical composition of free or particle-associated bacterial populations of the rumen. Canadian Journal of Animal Science, 78(1), 115-120.

Cohn, A., Bowman, M., Zilberman, D. \& O'Neill, K. (2011). The viability of cattle ranching intensification in Brazil as a strategy to spare land and mitigate greenhouse gas emissions. Working University of Copenhagen, 11, 1-40.

DeRamus, H. A., Clement, T. C., Giampola, D. D. \& Dickison, P. C. (2003). Methane emissions of beef cattle on forages. Journal of Environmental Quality, 32(1), 269-277.

Ellis, J. L., Kebreab, E., Odongo, N. E., McBride, B. W., Okine, E. K. \& France, J. (2007). Prediction of methane production from dairy and beef cattle. Journal of Dairy Science, 90(7), 3456-3466.

FAPRI. (2017). Food and Agricultural Policy Research Institute. Food and Agricultural Policy Research Institute, from http://www.fapri.iastate.edu/tools/outlook.aspx

Ferraz, J. B. S. \& Felício, P. E. (2010). Production systems - An example from Brazil. Meat Science, 84(2), 238-243.

Flemming, J., S, \& Freitas, R., J,S,. (2005). Avaliação do efeito de prebióticos (MOS), probióticos (Bacillus licheniformis e Bacillus subtilis) e promotor de crescimento na alimentação de frangos de corte. Archives of Veterinary Science, 10(2), 41-47.

Gattass, C. B. A., Morais, M. G., Abreu, U. G. P., Franco, G. L., Stein, J. \& Lempp, B. (2008). Efeito da suplementação com cultura de levedura na fermentação ruminal de bovinos de corte. Revista Brasileira de Zootecnia, 37(4), 711-716.

Geraci, J. I., Garciarena, A. D., Gagliostro, G. A., Beauchemin, K. A. \& Colombatto, D. (2012). Plant extracts containing cinnamaldehyde, eugenol and capsicum oleoresin added to feedlot cattle diets: Ruminal environment, short term intake pattern and animal performance. Animal Feed Science and Technology, 176(1-4), 123-130. doi: doi.org/10.1016/j.anifeedsci.2012.07.015

Goel, G. \& Makkar, H. P. (2012). Methane mitigation from ruminants using tannins and saponins. Tropical Animal Health and Production, 44(4), 729-739.

Hart, K. J., Yáñez-Ruiz, D. R., Duval, S. M., McEwan, N. R. \& Newbold, C. J. (2008). Plant extracts to manipulate rumen fermentation. Animal Feed Science and Technology, 147(1-3), 8-35.

Hegarty, R. S. \& Gerdes, R. (1999). Hydrogen production and transfer in the rumen. Recent Advances in Animal Nutrition in Australia, 12, 37-44.

Hess, H. D., Kreuzer, M., Díaz, T. E., Lascano, C. E., Carulla, J. E., Soliva, C. R. \& Machmüller, A. (2003). Saponin rich tropical fruits affect fermentation and methanogenesis in faunated and defaunated rumen fluid. Animal Feed Science and Technology, 109(1-4), 79-94.

Hook, S. E., Wright, A. D. G. \& McBride, B. W. (2010). Methanogens: methane producers of the rumen and mitigation strategies. Archaea, 2010(Article ID 945785), 11.

Hristov, A. N., McAllister, T. A. \& Cheng, K. J. (2000). Intraruminal supplementation with increasing levels of exogenous polysaccharide-degrading enzymes: effects on nutrient digestion in cattle fed a barley grain diet. Journal of Animal Science, 78(2), 477-487. 
Huws, S. A., Creevey, C. J., Oyama, L. B., Mizrahi, I., Denan, S. E., Popova, M., Morgavi, D. P. (2018). Addressing global ruminant agricultural challenges through understanding the rumen microbiome: Past, present and future. Frontiers in Microbiology, 9(2161), 1-33.

IPCC. (2006). - Intergovernamental Panel on Climate Change (2006). IGES: IPCC.

Ishino, Y., Komori, K., Cann, I. K. O. \& Koga, Y. (1998). A novel DNA polymerase family found in Archaea. Journal of Bacteriology, 180(8), 2232-2236.

Issakowicz, J., Bueno, M. S., Sampaio, A. C. K. \& Duarte, K. M. R. (2013). Effect of concentrate level and live yeast (Saccharomyces cerevisiae) supplementation on Texel lamb performance and carcass characteristics. Livestock Science, 155(1), 44-52.

Ito, R. H., Ducatti, T., Prado, J. M., Prado, I. M., Rotta, P. P., Valero, M. V., Silva, R. R. (2010). Soybean oil and linseed grains on performance and carcass characteristics of crossbred bulls finished in feedlot. Semina: Ciências Agrárias, 31(1), 259-268.

Jiménez-Colmenero, F. (2007). Healthier lipid formulation approaches in meat-based functional foods. Technological options for replacement of meat fats by non-meat fats. Trends in Food Science and Technology, 18(11), 567-578. doi: 10.1016/j.tifs.2007.05.006

Johnson, K. A. \& Johnson, D. E. (1995). Methane emissions from cattle. Journal of Animal Science, 73(8), 2483-2492.

Kesarcodi-Watson, A., Kaspar, H., Lategan, M. J. \& Gibson, L. (2008). Probiotics in aquaculture: the need, principles and mechanisms of action and screening processes. Aquaculture, 274(1), 1-14.

Kozloski, G. V. (2011). Bioquímica dos ruminantes (3a Ed. ed. Vol. 1). Santa Maria: Editora Universidade Federal de Santa Maria.

Lascano, C. E. \& Cárdenas, E. (2010). Alternatives for methane emission mitigation in livestock systems. Revista Brasileira de Zootecnia, 39, 175-182.

Martin, C., Morgavi, D. P. \& Doreau, M. (2010). Methane mitigation in ruminants: from microbe to the farm scale. Animal, 4(03), 351-365.

Massé, D. I., Masse, L., Claveau, S., Benchaar, C. \& Thomas, O. (2008). Methane emissions from manure storages. Transactions of the ASABE, 51(5), 1775-1781.

McAllister, T. A., Cheng, K.-J., Okine, E. K. \& Mathison, G. W. (1996). Dietary, environmental and microbiological aspects of methane production in ruminants. Canadian Journal of Animal Science, 76(2), 231-243.

Miller, T. L. (1995). Ecology of methane production and hydrogen sink in the rumen. In W. V. Engelhardt, S. Leonhard-Marek, G. Breves \& D. Giessecke (Eds.), Ruminant physiology: Digestion, metabolism, growth and reproduction (pp. 317-332). Stuttgart, Alemanha: Ferdinand Enke Verlag.

Monteiro, A. L. G., Faro, A. M. C. d. F., Peres, M. T. P., Batista, R., Poli, C. H. E. C. \& Villalba, J. J. (2018). The role of small ruminants on global climate change. Acta Scientiarum. Animal Sciences, 40(e43124), 1-11.

Muetzel, S. \& Clark, H. (2015). Methane emissions from sheep fed fresh pasture. New Zealand Journal of Agricultural Research, 58(4), 472-489.

Ornaghi, M. G., Passetti, R. A. C., Torrecilhas, J. A., Mottin, C., Vital, A. C. P., Gurerrero, A., Prado, I. N. (2017). Essential oils in the diet of young bulls: Effect on animal performance, digestibility, temperament, feeding behaviour and carcass characteristics. Animal Feed Science and Technology, 234, 274-283.

Palmquist, D. (1989). Suplementação de lipídios para vacas em lactação. Simpósio sobre nutrição de ruminantes, 6(1989), 11-25.

Palmquist, D. L. \& Jenkins, T. C. (1980). Fat in lactation rations: Review. Journal of Dairy Science, 63(1), 1-14. doi: 10.3168/jds.S0022-0302(80)82881-5

Palmquist, D. L. \& Mattos, W. R. S. (2011). Metabolismo de lipídios. In T. T. Berchielli, A. V. Pires \& S. G. Oliveira (Eds.), Nutrição de Ruminantes (Vol. 1, pp. 299-322). Jaboticabal, Brazil: FUNEP.

Pereira, L. G. R. (2013). Métodos de avaliação e estratégias de mitigação de metano entérico em ruminantes. Revista Colombiana de Ciencias Pecuaria(26), 264-277. 
Pinares-Patiño, C. S., Waghorn, G. C., Machmüller, A., Vlaming, B., Molano, G., Cavanagh, A. \& Clark, H. (2007). Methane emissions and digestive physiology of non-lactating dairy cows fed pasture forage. Canadian Journal of Animal Science, 87(4), 601-613. doi: 10.4141/CJAS06023

Pinedo, L. A., Jacomini, A., Vendramin, D., Nolasco, F., Júnior, L., Santos, M. A., Selem, A. S. M. A. (2009). Inventário de emissões de gás metano provenientes da fermentação entérica e óxido nitroso do manejo de dejetos animais-período 1990 a 2005. PUBVET, 3(11), 1-7.

Ramírez-Restrepo, C. A., Tan, C., O’Neill, C. J., López-Villalobos, N., Padmanabha, J., Wang, J. \& McSweeney, C. S. (2016). Methane production, fermentation characteristics, and microbial profiles in the rumen of tropical cattle fed tea seed saponin supplementation. Animal Feed Science and Technology, 216, 58-67.

Smith, P., Martino, D., Cai, Z., Gwary, D., Janzen, H., Kumar, P., Towprayoon, S. (2007). Policy and technological constraints to implementation of greenhouse gas mitigation options in agriculture. Agriculture, Ecosystems \& Environment, 118(1-4), 6-28.

Steinfeld, H., Gerber, P., Wassenaar, T. D., Castel, V., Rosales, M. \& de Haan, C. (2006). Livestock's long shadow: environmental issues and options. Roma, Italy: Food \& Agriculture Organization.

Tedeschi, L. O., Fox, D. G. \& Tylutki, T. P. (2003). Potential environmental benefits of ionophores in ruminant diets. Journal of Environmental Quality, 32(5), 1591-1602.

Wallace, R. J., McEwan, N. R., McIntosh, F. M., Teferedegne, B. \& Newbold, C. J. (2002). Natural products as manipulators of rumen fermentation. Asian Australasian Journal of Animal Sciences, 15(10), 1458-1468.

Zeoula, L. M., Beleze, J. R. F., Maeda, E. M., Simioni, F. L., Geron, L. J. V. \& Rigolon, L. P. (2011). Yeast culture or monensin in the diet of cattle and buffalos on ruminal fermentation and microbial efficiency. Acta Scienciarum. Animal Sciences, 33(4), 379-386.

Zhai, X., Lu, T., Tang, S., Liu, X., Ma, X., Han, G., Wang, C. (2015). Methane emission from sheep respiration and sheepfolds during the grazing season in a desert grassland. The Open Atmospheric Science Journal, 9(1), 23-28.

Zinn, R. A. (1987). Influence of lasalocid and monensin plus tylosin on comparative feeding value of steam-flaked versus dry-rolled corn in diets for feedlot cattle. Journal of Animal Science, 65(1), 256266.

Zotti, C. A. \& Paulino, V. T. (2009). Metano na produção animal: emissão e minimização de seu impacto. Nova Odessa, São Paulo, Brasil: Instituto de Zootecnia.

Recebido: 9 dezembro, 2018.

Aprovado: 29 dezembro, 2018.

Publicado: 30 janeiro, 20189.

Licenciamento: Este artigo é publicado na modalidade Acesso Aberto sob a licença Creative Commons Atribuição 4.0 (CC-BY 4.0), a qual permite uso irrestrito, distribuição, reprodução em qualquer meio, desde que o autor e a fonte sejam devidamente creditados. 